\title{
Automated tube voltage selection and adapted contrast media injection protocols in CT angiography of the thoracoabdominal aorta
}

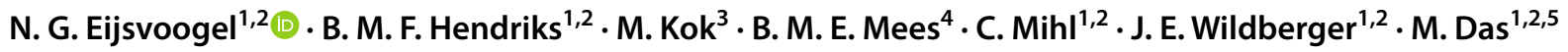

Received: 17 August 2020 / Revised: 11 March 2021 / Accepted: 25 March 2021 / Published online: 11 April 2021

(c) The Author(s) 2021

\begin{abstract}
Purpose The aim was to assess the image quality (IQ) in computed tomography angiography (CTA) of the thoracoabdominal aorta utilizing automated tube voltage selection (ATVS) with a subsequently adapted contrast media (CM) injection protocol. Materials and methods A total of 104 consecutive patients referred for CTA of the thoracoabdominal aorta were included. Scans were acquired on a 3rd-generation DSCT using ATVS with a quality reference tube voltage and current of $100 \mathrm{kV}$ and $150 \mathrm{mAs}$. CM protocols were adapted to $\mathrm{kV}$ settings by modifying iodine delivery rate (IDR) whilst maintaining an identical injection time (13.3 s): $0.9 \mathrm{gI} / \mathrm{s}(70 \mathrm{kV}), 1.0 \mathrm{gI} / \mathrm{s}(80 \mathrm{kV}), 1.1 \mathrm{gI} / \mathrm{s}(90 \mathrm{kV}) 1.2 \mathrm{gI} / \mathrm{s}(100 \mathrm{kV})$. Both objective (attenuation, contrast-to-noise and signal-to-noise) and subjective (4-point Likert scale: $1=$ poor $/ 2=$ sufficient $/ 3=$ good $/ 4=$ excellent) IQ were assessed.

Results ATVS assigned a $70 \mathrm{kV}(n=88)$ and $90 \mathrm{kV}(n=16)$ protocol in most patients. Fewer patients were assigned to an $80 \mathrm{kV}(n=4)$ and $100 \mathrm{kV}(n=1)$ protocol, these protocols were, therefore, excluded from further analysis. Attenuation on all designated levels of the thoracoabdominal aorta was diagnostic in $99.0 \%$ of the scans; $87 / 88$ scans (98.9\%) in the $70 \mathrm{kV}$ group and in $16 / 16(100 \%)$ in the $90 \mathrm{kV}$ group. Overall mean attenuation was $349 \pm 72 \mathrm{HU}$ for $70 \mathrm{kV}$ and $310 \pm 43 \mathrm{HU}$ for $90 \mathrm{kV}$. Subjective IQ was diagnostic in all scans. Overall effective radiation dose for $70 \mathrm{kV}$ and $90 \mathrm{kV}$ was $1.8 \pm 0.2 \mathrm{mSv}$ and $3.4 \pm 0.7 \mathrm{mSv}$, respectively.

Conclusions Adaptation of CM injection protocols (IDR) to ATVS in CTA of the aorta—scanned with $70 \mathrm{kV}$ and $90 \mathrm{kV}$-is feasible and results in diagnostic image quality.
\end{abstract}

Keywords Multidetector Computed Tomography $\cdot$ Angiography $\cdot$ Contrast media $\cdot$ Radiation dosage $\cdot$ Image enhancement

Abbreviations

PC-AKI Post-contrast acute kidney injury

ATVS Automated tube voltage selection

N. G. Eijsvoogel

nienke.eijsvoogel@mumc.nl

1 Department of Radiology and Nuclear Medicine, Maastricht University Medical Center, P. Debyelaan 25, PO Box 5800, 6202 AZ Maastricht, The Netherlands

2 CARIM School for Cardiovascular Diseases, Maastricht University Medical Center, Maastricht, The Netherlands

3 Department of Radiology and Nuclear Medicine, University Medical Centre Utrecht, Utrecht, The Netherlands

4 Department of Vascular Surgery, Maastricht University Medical Center, P. Debyelaan 25, PO Box 5800, 6202 AZ Maastricht, The Netherlands

5 Department of Diagnostic and Interventional Radiology, Helios Kliniken Duisburg, An der Abtei 7-11, 47166 Duisburg, Germany
BMI Body mass index

CM Contrast media

CNR Contrast-to-noise ratio

CTA Computed tomography angiography

DSCT Dual source computed tomography

IDR Iodine delivery rate

IQ Image quality

SNR Signal-to-noise ratio

\section{Introduction}

Computed Tomography Angiography (CTA) of the aorta is an important imaging method with high diagnostic accuracy for the detection of various aortic diseases [1-4]. High diagnostic accuracy relies on sufficient intravascular iodine attenuation and contrast-to-noise ratio (CNR) [5]. These factors depend on various features regarding contrast media (CM) administration (e.g. iodine concentration and iodine 
delivery rate [IDR]), scan protocol (e.g. tube voltage and tube current) and patient related factors (e.g. body weight, heart rate and cardiac output) [6]. Body weight has a substantial impact on vascular attenuation. A fixed injection protocol causes a large variation between different weight groups indicating suboptimal use of CM in different patient weight categories. Patients with a low body weight require less CM volume to be injected in comparison to patients with a higher body weight for diagnostic attenuation. Therefore, optimisation of scan and injection protocols is a must, and various beforementioned features can be used. With regard to the $\mathrm{CM}$ injection protocol, the IDR is considered the most important factor [7].

One potential disadvantage of CTA of the aorta is the possible development of post-contrast acute kidney injury (PC-AKI) after CM administration. A higher CM volume might increase the risk of developing PC-AKI, especially in patients with multiple pre-existent risk factors for PC-AKI undergoing CTA of the aorta [8]. Although the development of PC-AKI has been a topic of discussion $[9,10]$, guidelines still advise to use as low CM volumes as possible. With the optimisation of CM injection protocols, patients only receive the amount of $\mathrm{CM}$ volume needed for a diagnostic scan. Another concern is about the long-term, stochastic risks of CT radiation dose, especially in younger patients undergoing frequent follow-up examinations in aneurysm surveillance or endovascular treatment follow-up [3, 11, 12]. Therefore, in CT imaging the "as low as reasonably achievable" (ALARA) principle always applies. Current scanner technology provides sufficient tube current output on lower $\mathrm{kV}$ levels, which aids in reducing overall radiation dose. Furthermore, automated tube voltage selection (ATVS) allows for maintained image quality (IQ) with lower overall radiation doses for patients [13-15].

ATVS is a software program which automatically adapt scan settings to the individual patient. ATVS uses scout scans (with information on patient size and tissue density) to automatically adjust the $\mathrm{kV}$ setting and $\mathrm{mAs}$ to reach a certain CNR level. For slimmer patients, a lower $\mathrm{kV}$ setting is selected, and for bigger patients, a higher $\mathrm{kV}$ setting. The use of lower $\mathrm{kV}$ settings is accompanied by higher iodine attenuation, explained by the fact that mean photon energy (of the lower $\mathrm{kV}$ ) in the $\mathrm{X}$-ray beam moves closer to the K-edge of Iodine (33.2 keV) [16]. Vice versa, a higher $\mathrm{kV}$ setting is accompanied by a lower iodine attenuation. Therefore, the $\mathrm{CM}$ injection protocol should be adjusted to the $\mathrm{kV}$ setting. With a lower tube voltage, a smaller amount of CM can be applied to achieve the same intravascular attenuation level [17-20]. Canstein et al. found that with every $10 \mathrm{kV}$ subtraction, the iodine dose can be reduced by $10 \%$ (10-to- 10 rule) and vice versa [21]. This was tested and proven feasible in a previous study at $80 \mathrm{kV}$ and $100 \mathrm{kV}$ by adjusting the IDR [22].The aim of this study was to assess feasibility and image quality of CM injection protocols (IDR) adapted to ATVS in a cohort of patients undergoing CTA of the aorta.

\section{Materials and methods}

\section{Ethics and patient population}

The study design was approved by the local ethical committee and the institutional review board. A waiver of written informed consent was obtained from the local ethical committee (METC 15-4-247). Between January 2016 and April 2017, all patients referred for CTA of the thoracoabdominal aorta were considered eligible for inclusion. A non-randomized study design was deemed appropriate, since ATVS takes the patient size and scan length into account when assigning the optimal $\mathrm{kV}$ setting.

The following exclusion criteria for CTA in our department were applicable; allergy to iodinated CM, pregnancy, and renal insufficiency (defined as glomerular filtration rate $(\mathrm{GFR})<30 \mathrm{~mL} / \mathrm{min} / 1.73 \mathrm{~m}^{2}$ ). Furthermore, patients were excluded if a combined examination protocol was applied, e.g. additional portal venous assessment of the upper abdomen, as this required a different $\mathrm{CM}$ protocol with larger volumes for parenchymal enhancement.

Patient characteristics (age, sex, weight, height and BMI) were collected and analysed. Patients were analysed in groups according to the $\mathrm{kV}$ setting designated by automated tube voltage selection (ATVS; CAREkVTM, Siemens Healthineers, Forchheim, Germany): the possible $\mathrm{kV}$ settings in this study ranged from 70 to $120 \mathrm{kV}$, in increments of $10 \mathrm{kV}$.

\section{CTA scan protocol}

Scans were performed using a 3rd generation dual-source CT scanner (DSCT, Somatom Force, Siemens) with a slice collimation of $2 \times 192 \times 0.6 \mathrm{~mm}$; gantry rotation time of $0.5 \mathrm{~s}$. A pitch value of 0.6 was chosen to increase scan time and prevent the scanner from outrunning the $\mathrm{CM}$ bolus in the aorta. The scan acquisition time varied depending on scan range. All patients received a scan protocol with a quality reference tube voltage of $100 \mathrm{kV}_{\text {ref }}$ and quality reference tube current of $150 \mathrm{mAs}_{\text {ref }}$ (CareDose 4D ${ }^{\mathrm{TM}}$, Siemens). The slider position in the current study was set at 11; the vascular setting. Scan delay was determined via bolus tracking by placing a circular region of interest (ROI) in the descending aorta at the level of the pulmonary trunk. A threshold of $100 \mathrm{HU}$ was used with a post bolus tracking delay of $5 \mathrm{~s}$ for table movement followed by a breath hold command. Image reconstruction was performed on $1 \mathrm{~mm}$ slices with an increment of $0.8 \mathrm{~mm}$ using an iterative reconstruction vascular kernel (Bv36; Advanced Modelled Iterative Reconstruction [ADMIRE], strength 3). 
CAREkVTM is ATVS software developed to reduce radiation dose while keeping CNR constant [15]. Scoutscans and the resulting patient attenuation are used to calculate patient-specific $\mathrm{mAs}$ curves for all possible $\mathrm{kV}$ settings. These mAs curves are composed with help of different parameters, e.g. scan length, patient anatomy, scan type and tissue of interest. The scanner calculates estimated radiation dose and the optimal dose efficiency in terms of $\mathrm{kV}$ and $\mathrm{mAs}$ combination is determined for each individual patient [23].

Radiation dose monitoring software (Radimetrics ${ }^{\mathrm{TM}}$, Bayer) was used to record the CTDIvol (mGy), doselength product (DLP; $\mathrm{mGy}^{*} \mathrm{~cm}$ ) and the effective dose $(\mathrm{mSv})$ for each CTA. The software estimates the effective dose using patient age and sex to determine accurate tissue weighing factors as described by the ICRP publication 103 [24].

\section{CM injection protocol}

CM consisted of $300 \mathrm{mg} \mathrm{1/mL} \mathrm{Iopromide} \mathrm{(Ultravist,} \mathrm{Bayer}$ Healthcare, Berlin, Germany), prewarmed to body temperature $\left(37^{\circ} \mathrm{C} ; 99^{\circ} \mathrm{F}\right)$, injected using a dual-head CT power injector (Stellant, Bayer).

Patients received a $\mathrm{CM}$ injection protocol according to the selected $\mathrm{kV}$ setting. The various $\mathrm{CM}$ injection parameters are listed in Table 1 . A clinically validated $\mathrm{CM}$ injection protocol for $80 \mathrm{kV}$ was used and adapted for the other $\mathrm{kV}$ settings $(70 \mathrm{kV}$ and $90 \mathrm{kV}, 100 \mathrm{kV}, 110 \mathrm{kV}$ and $120 \mathrm{kV}$ ) [22]. The IDR of $80 \mathrm{kV}$ was known, and for every $10 \mathrm{kV}$ increment subtraction or addition, the IDR was decreased or increased with $10 \%$ [21]. Since the CM concentration was known and a fixed injection time (IT) of $13.3 \mathrm{~s}$ was used, the other injection protocol parameters could be calculated. A saline chaser was injected afterwards with a volume of $40 \mathrm{~mL}$ at the same flow rate as the $\mathrm{CM}$ bolus.

Table 1 Injection protocols per $\mathrm{kV}$ setting

\begin{tabular}{lllll}
\hline kV setting & $\begin{array}{l}\mathrm{CM} \text { volume } \\
(\mathrm{mL})\end{array}$ & $\begin{array}{l}\text { Flow rate } \\
(\mathrm{mL} / \mathrm{s})\end{array}$ & IT $(\mathrm{s})$ & IDR $(\mathrm{g} \mathrm{I} / \mathrm{s})$ \\
\hline \multicolumn{4}{l}{ Thoracoabdominal aorta } \\
70 & 40 & 3.0 & 13.3 & 0.9 \\
80 & 44 & 3.3 & 13.3 & 1.0 \\
90 & 49 & 3.7 & 13.3 & 1.1 \\
100 & 53 & 4.0 & 13.3 & 1.2 \\
110 & 57 & 4.3 & 13.3 & 1.3 \\
120 & 63 & 4.7 & 13.3 & 1.4 \\
\hline
\end{tabular}

ATVS automated tube voltage selection, IT injection time, IDR iodine delivery rate

\section{Data analysis}

All CT-images were analysed using axial slices and multiplanar reconstruction (MPR) on a dedicated post processing workstation (Syngo-Via ${ }^{\mathrm{TM}}$, Siemens Healthineers). To assess the true axial planes perpendicular to the vascular wall on multiple pre-defined levels of the aorta, a centreline was automatically drawn in the aorta and both right and left iliac and femoral arteries. Curved multiplanar reconstructions (MPRs) were used to draw region of interests (ROIs) in the aorta (for examples, see Figs. 1 and 2).

\section{Image analysis: primary endpoint}

The primary endpoint was the proportion of scans with a mean intravascular attenuation above $200 \mathrm{HU}$ at multiple pre-defined vascular segments in the aorta (see below). The minimal diagnostic attenuation value for the evaluation of aortic pathologies is considered to be $200 \mathrm{HU}$ $[25,26]$. Objective image quality analysis was performed by one radiology resident (N.E, 5 years of experience) by measuring intravascular attenuation in Hounsfield Units (HU) in predefined vascular segments. ROI's were manually drawn as large as possible in the ascending aorta (AA), aortic arch (Arch), descending aorta (DA), abdominal aorta (AbA), right and left common iliac artery (RCIA and LCIA) and right and left common femoral arteries (RCFA and LCFA) [20]. Special care was taken to avoid measurements of the vessel wall, stents and atherosclerotic plaques. Image noise was defined as the standard deviation (SD) of the intravascular attenuation and measured at the level of the AbA [27]. Overall mean intravascular attenuation was defined as the mean of the sum of all different anatomic levels in one scan. Overall mean intravascular attenuation (per-patient) and attenuation at the different anatomic levels (per-segment) were reported.

\section{Image analysis: secondary endpoints}

CNR was calculated as intravascular attenuation minus intramuscular attenuation, divided by the SD of the intramuscular attenuation $[19,20,22,28]$. SNR was calculated as intravascular attenuation divided by the SD of the intravascular attenuation $[19,22,27]$.

Subjective image quality was determined by two readers in consensus (N.E. and M.D.) using a four-point Likert scale with regard to intravascular attenuation, presence of artefacts and image noise: $1=$ non-diagnostic image quality, 2 = sufficient image quality, $3=$ good image quality, $4=$ excellent image quality. 
Fig. 1 Example of curved MPR of the thoracoabdominal aorta. Patient with a BMI of $28 \mathrm{~kg} / \mathrm{m}^{2}$; scan protocol: $90 \mathrm{kV}, 164 \mathrm{mAs}_{\mathrm{eff}}$, CTDIvol $4.75 \mathrm{mGy}$, effective radiation dose of $4 \mathrm{mSv}$, image quality was graded excellent. Threedimensional reconstruction of the entire aorta (left) shows an abdominal aortic aneurysm (AAA). Vessel definition, with help of a centreline drawn in the aorta (right), and axial views (small boxes) on the same anatomical level (stripe) also show a short dissection. The axial views are used to measure intravascular attenuation, and vessel wall and plaques can be avoided with more precision

Fig. 2 Example of curved MPR of the thoracoabdominal aorta. Patient with a BMI of $20 \mathrm{~kg} / \mathrm{m}^{2}$; scan protocol: $70 \mathrm{kV}, 172 \mathrm{mAs}_{\mathrm{eff}}$, CTDIvol $2.02 \mathrm{mGy}$, effective radiation dose of $1.6 \mathrm{mSv}$, image quality was graded excellent. Threedimensional reconstruction of the entire aorta (left) shows an abdominal aortic aneurysm (AAA). The axial views are used to measure intravascular attenuation, and vessel wall and plaques can be avoided with more precision
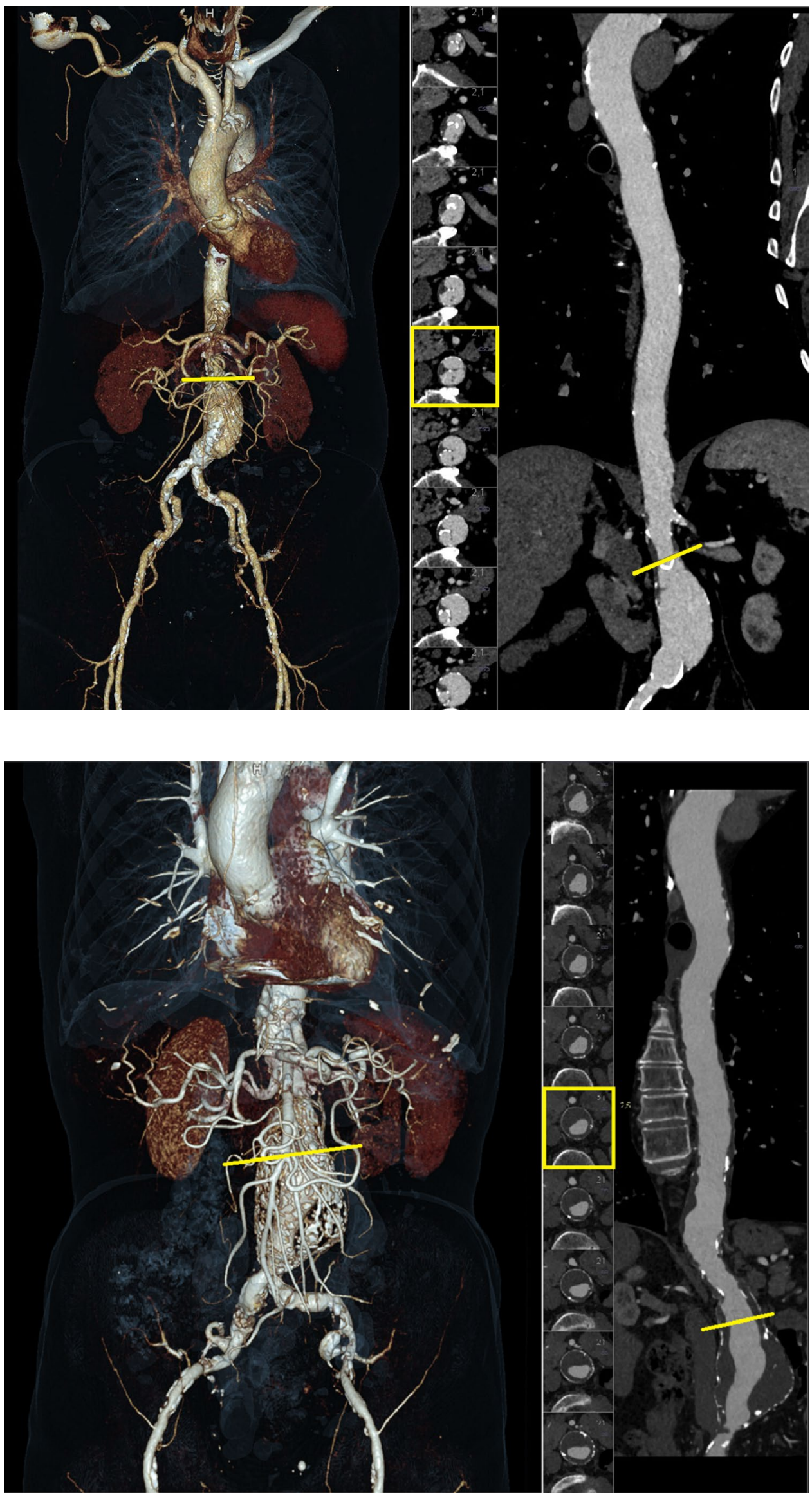


\section{Statistical analysis}

Statistical analysis was performed with Statistical Package for the Social Sciences (IBM SPSS statistics, Chicago IL, USA, version 25.0). Continuous variables were expressed as mean \pm standard deviation (SD) and categorical variables as absolute numbers and percentages (\%). Categorical variables were expressed as absolute numbers and percentages.

\section{Results}

\section{Patient characteristics}

A total of 153 consecutive patients referred for CTA of the thoracoabdominal aorta were considered eligible for inclusion. A total of 44 patients were excluded because aberrant scan parameters or a different $\mathrm{CM}$ injection protocol was used ( $n=42$; e.g. a multiphase scan protocol was used instead of the requested study protocol), or because the aortic tract was not depicted in its entirety $(n=2)$. The use of ATVS resulted in the following group distribution: 88 patients $(80.7 \%)$ for $70 \mathrm{kV}$, four patients $(3.7 \%)$ for $80 \mathrm{kV}$, 16 patients (14.7\%) for $90 \mathrm{kV}$ and one patient for $100 \mathrm{kV}$ $(0.9 \%)$. ATVS did not select a $110 \mathrm{kV}$ or $120 \mathrm{kV}$ setting for any patient. Since the 80 and $100 \mathrm{kV}$ groups consisted of less than five patients each, these were excluded for detailed statistical analysis. Thus, a total of 104 patients were included for further analysis.

Mean age in the $70 \mathrm{kV}$ and $90 \mathrm{kV}$ group was $68.2 \pm 12.5$ years and $66.5 \pm 11.6$ years, respectively. Mean weight was $78.5 \pm 16.8 \mathrm{~kg}$ in the $70 \mathrm{kV}$ group and

Table 2 Patient characteristics and scan indications for different groups

\begin{tabular}{lll}
\hline Characteristic & $70 \mathrm{kV}(n=88)$ & $90 \mathrm{kV}(n=16)$ \\
\hline Age (year) & $68.2 \pm 12.5$ & $66.5 \pm 11.6$ \\
Sex & & \\
$\quad$ Male $n(\%)$ & $67(76.4)$ & $13(81.3)$ \\
Female $n(\%)$ & $21(23.9)$ & $3(18.8)$ \\
Height $(\mathrm{m})$ & $1.73 \pm 0.10$ & $1.72 \pm 0.10$ \\
Weight $(\mathrm{kg})$ & $78.5 \pm 16.8$ & $83.6 \pm 19.7$ \\
BMI $\left(\mathrm{kg} / \mathrm{m}^{2}\right)$ & $26.0 \pm 5.0$ & $28.0 \pm 4.7$ \\
Indication scan: $n(\%)$ & & \\
Aneurysm & $33(37.5)$ & $8(50.0)$ \\
Post-surgery & $31(35.2)$ & $2(12.5)$ \\
Dissection & $15(17.0)$ & $2(12.5)$ \\
Other & $9(10.2)$ & $4(25.0)$ \\
\hline
\end{tabular}

Values are presented as means \pm standard deviation, or absolute numbers and percentages between parentheses

BMI Body Mass Index
$83.6 \pm 19.7$ in the $90 \mathrm{kV}$ group. A total of 52 patients $(50 \%)$ had a BMI $\geq 25 \mathrm{~kg} / \mathrm{m}^{2}$ (40 patients in the $70 \mathrm{kV}$ group and 12 patients in the $90 \mathrm{kV}$ group), the rest of the patients had a BMI $<25 \mathrm{~kg} / \mathrm{m}^{2}$. All patient characteristics are depicted in Table 2.

\section{Radiation dose and injection parameters}

All radiation dose parameters are listed in Table 3. Mean effective radiation dose was $1.8 \pm 0.2 \mathrm{mSv}$ in the $70 \mathrm{kV}$ group and $3.4 \pm 0.7 \mathrm{mSv}$ in the $90 \mathrm{kV}$ group.

Mean $\mathrm{CM}$ volumes and flow rates for the different $\mathrm{kV}$ settings were $39.9 \pm 0.9 \mathrm{~mL}$ and $2.9 \pm 0.1 \mathrm{~mL} / \mathrm{s}$ for $70 \mathrm{kV}$ and $48.9 \pm 0.1 \mathrm{~mL}$ and $3.6 \pm 0.0 \mathrm{~mL} / \mathrm{s}$ for $90 \mathrm{kV}$ (Table 4).

\section{Image quality-per-patient level}

Mean intravascular attenuation on a per-patient level was diagnostic ( $\geq 200 \mathrm{HU})$ in $99.0 \%$ of all scans; mean intravascular attenuation was diagnostic in $87 / 88$ scans $(98.9 \%)$ in the $70 \mathrm{kV}$ group and in all scans $(16 / 16 ; 100 \%)$ in the $90 \mathrm{kV}$ group. In one patient of the $70 \mathrm{kV}$ group, the scanner outrunned the bolus. Hence, the attenuation level was below $200 \mathrm{HU}$ in four distal segments (i.e. RCIA, LCIA, RCFA, LCFA). Overall mean attenuation for different $\mathrm{kV}$ groups was $349 \pm 72 \mathrm{HU}$ for $70 \mathrm{kV}$ and $310 \pm 43 \mathrm{HU}$ for $90 \mathrm{kV}$. Overall mean CNR was $15 \pm 6$ for the $70 \mathrm{kV}$ and $18 \pm 7$ for the $90 \mathrm{kV}$ group. Overall mean SNR was $11 \pm 4$ for the $70 \mathrm{kV}$ and $14 \pm 4$ for the $90 \mathrm{kV}$ group.

All image quality parameters are depicted in Table 5.

Table 3 Radiation dose different $\mathrm{kV}$ settings

\begin{tabular}{lcc}
\hline Parameter & $70 \mathrm{kV}(n=88)$ & $90 \mathrm{kV}(n=16)$ \\
\hline Effective tube current (mAs) & $211 \pm 40$ & $163 \pm 50$ \\
CTDI $_{\mathrm{vol}}(\mathrm{mGy})$ & $2.5 \pm 0.5$ & $4.7 \pm 1.4$ \\
DLP $\left(\mathrm{mGy}{ }^{*} \mathrm{~cm}\right)$ & $176 \pm 44$ & $314 \pm 93$ \\
Effective dose $(\mathrm{mSv})$ & $1.8 \pm 0.2$ & $3.4 \pm 0.7$ \\
\hline
\end{tabular}

Values are presented as means \pm standard deviation

$C T D I$ computed tomography dose index volume, DLP dose length product

Table 4 Injection parameters for different scan ranges and $\mathrm{kV}$ settings

\begin{tabular}{lcc}
\hline Contrast injection parameter & $70 \mathrm{kV}(n=88)$ & $90 \mathrm{kV}(n=16)$ \\
\hline Mean volume (mL) & $39.9 \pm 0.9$ & $48.9 \pm 0.1$ \\
Mean flow rate (mL/s) & $2.9 \pm 0.1$ & $3.6 \pm 0.0$ \\
IT (s) & $13.9 \pm 0.8$ & $13.6 \pm 0.1$ \\
Peak pressure (psi) & $68.4 \pm 18.7$ & $68.0 \pm 13.0$ \\
\hline
\end{tabular}

Values are presented as means \pm standard deviation

IT injection time 
Table 5 Quantitative and qualitative IQ for different $\mathrm{kV}$ settings

\begin{tabular}{lll}
\hline Parameters & $70 \mathrm{kV}(n=88)$ & $90 \mathrm{kV}(n=16)$ \\
\hline Mean attenuation (HU) & $349 \pm 72$ & $310 \pm 43$ \\
Mean image noise (SD) & $30 \pm 6$ & $23 \pm 3$ \\
Mean CNR & $15 \pm 6$ & $18 \pm 7$ \\
Mean SNR & $11 \pm 4$ & $14 \pm 4$ \\
Likert scale & & \\
Non-diagnostic & - & - \\
Sufficient & $9(10.2)$ & - \\
Good & $19(21.6)$ & $5(31.3)$ \\
Excellent & $60(68.2)$ & $11(68.8)$ \\
\hline
\end{tabular}

Values are presented as means \pm standard deviation

$C N R$ contrast to noise ratio, $S N R$ signal to noise ratio

\section{Image quality per-segment level}

Attenuation on a per-segment level was diagnostic in $94.8 \%$ of all scans ( $\geq 200 \mathrm{HU}$ ). Figures 3 and 4 show the attenuation and corresponding CNR values at the different anatomic levels of the aorta. Attenuation fell below 200 $\mathrm{HU}$ in the abdominal and lower levels of the aorta in 13 scans of the $70 \mathrm{kV}(14.8 \%)$ and two scans of the $90 \mathrm{kV}$ group (12.5\%) (AbA, RCIA, LCIA, RCFA and LCFA) due to the scanner outrunning the bolus $(n=10 ; 8$ in $80 \mathrm{kV}$ and 2 in $90 \mathrm{kV})$, aortic stenosis $(n=2)$, aortic dissection $(n=2)$ and high BMI $\left(29.7 \mathrm{~kg} / \mathrm{m}^{3}\right)$ with a $70 \mathrm{kV}$ protocol $(n=1)$.

\section{Discussion}

Adaptation of IDR to ATVS resulted in a diagnostic mean overall intravascular attenuation of the thoracoabdominal aorta, a sufficiently high CNR and a sufficient SNR in nearly all $(99.0 \%)$ scans. Furthermore, the use of ATVS predominantly resulted in an image acquisition with low $\mathrm{kV}$ settings (e.g. $70 \mathrm{kV}$ and $90 \mathrm{kV}$ ). By using the attenuation effect of low $\mathrm{kV}$ settings drawing closer to the $\mathrm{K}$-edge of iodine, $\mathrm{CM}$ volumes of $40 \mathrm{~mL}(70 \mathrm{kV})$ and $46 \mathrm{~mL}(90 \mathrm{kV})$ were used without loss of diagnostic overall image quality.

The current study shows that with IDR adapted to ATVS, a diagnostic objective and subjective image quality can be achieved in nearly all scans. In some scans the attenuation fell $<200 \mathrm{HU}$ due to the scanner outrunning the CM bolus, a large abdominal aortic aneurysm (AAA), an aortic stenosis resulting in a decreased attenuation, an extensive thoracoabdominal dissection were the contrast filled the false instead of the true lumen, or a patient with a high BMI $(29.7 \mathrm{~kg} /$ $\mathrm{m}^{2}$ ) scanned with $70 \mathrm{kV}$, where a low CM volume of $40 \mathrm{~mL}$ was administered. Figure 3 shows a lower mean intravascular attenuation in the peripheral arteries and a relatively large SD in the $70 \mathrm{kV}$ group. The first can be explained by the scanner outrunning the CM bolus peripherally in the patients with a large aneurysm or significant stenosis. In this situation, it is possible that the table speed was too fast, and a longer CM bolus (e.g. $46 \mathrm{~mL}$ in the $90 \mathrm{kV}$ group) or a decreased flow rate is needed to widen the peak of the enhancement curve to prevent this from happening. Another solution could be the use of a double-level test bolus to
Fig. 3 Boxplot shows attenuation at different anatomic levels of the aorta for different scan protocols: $70 \mathrm{kV}$ and $90 \mathrm{kV}$ as assigned by ATVS

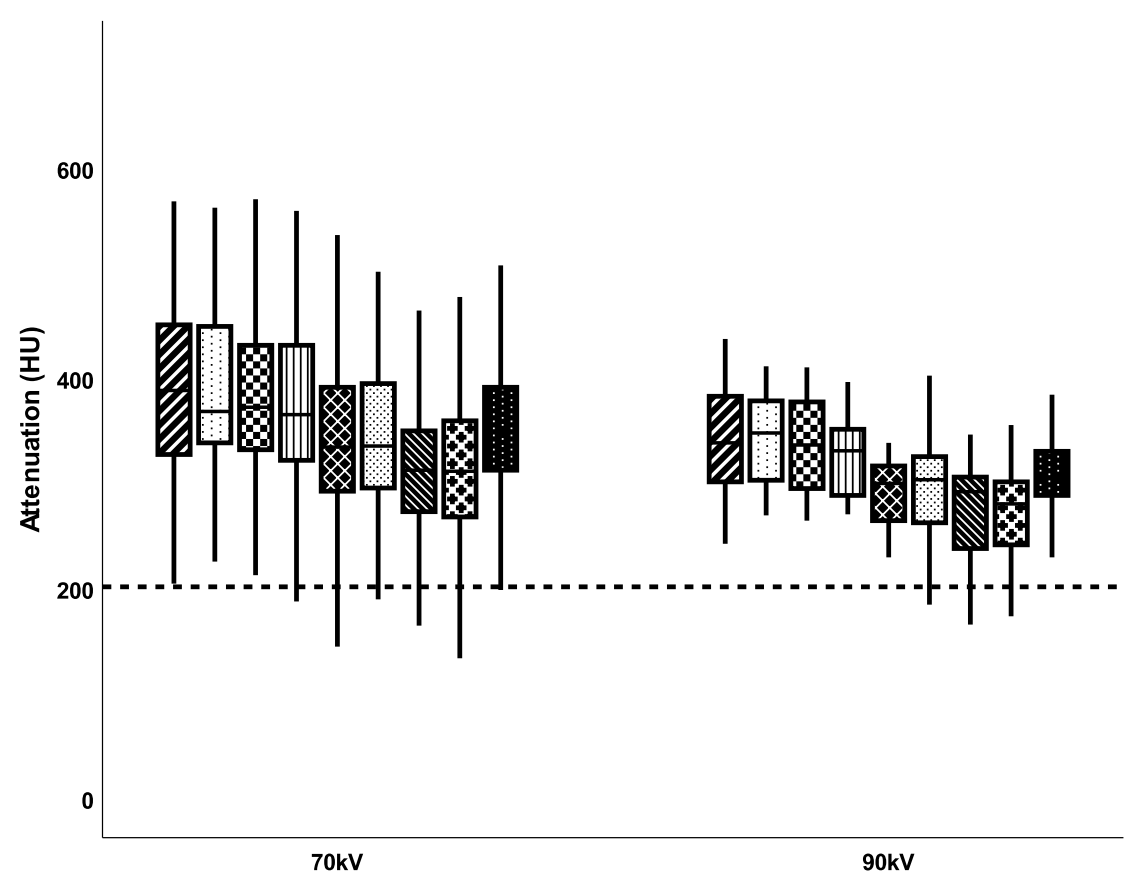

TAA :Arch BDA II $\mathrm{AbA}$ X. RCIA 2 LCIA NRCFA FlCFA :meanHU 
Fig. 4 Boxplot shows CNR at different anatomic levels of the aorta for different scan protocols: $70 \mathrm{kV}$ and $90 \mathrm{kV}$ as assigned by ATVS

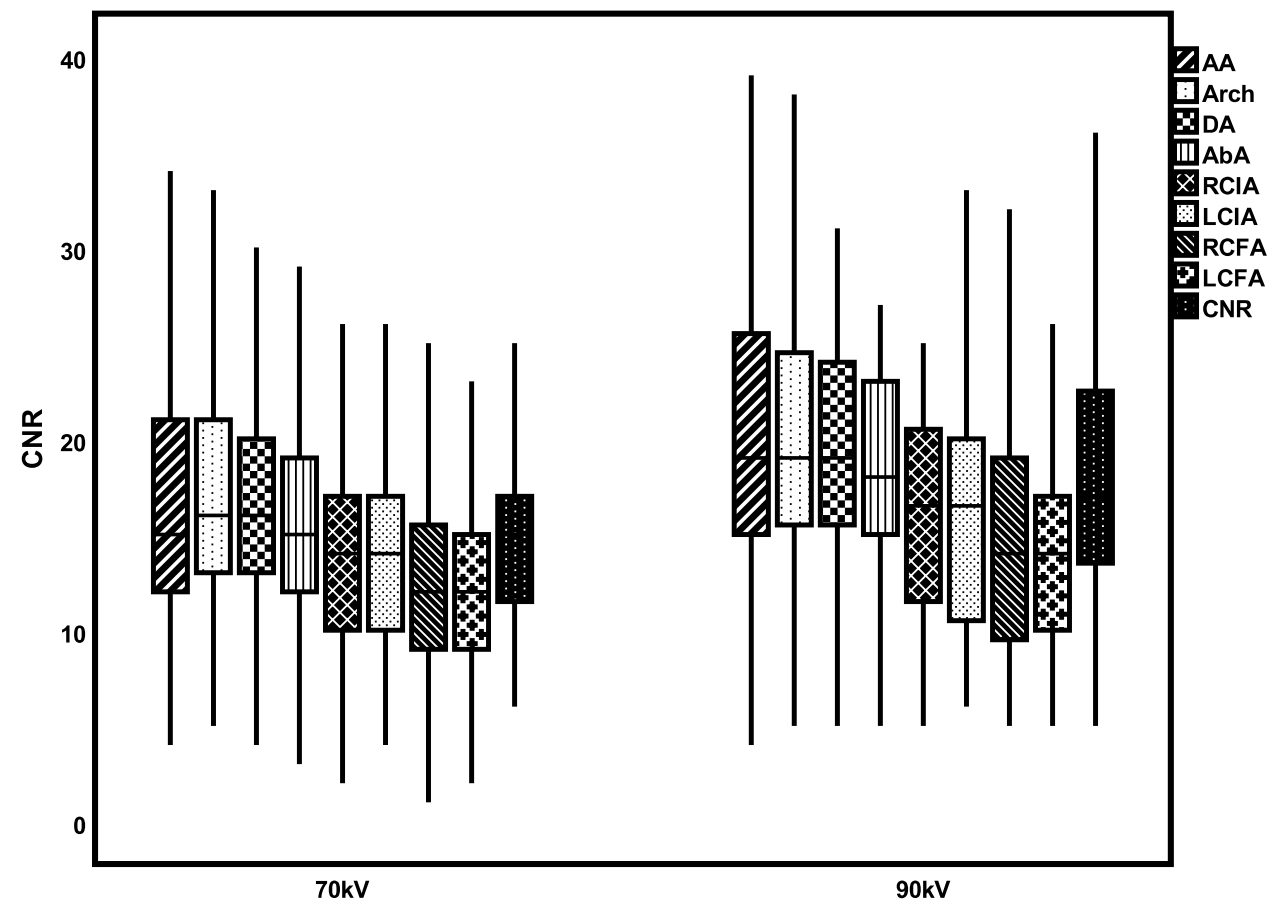

calculate the individual injection duration [29]. The wide SD could be due to the large variations in body size between the patients. Patient with a high body weight (or BMI) have an increased blood volume compared to slimmer patients. Since $\mathrm{CM}$ is diluted by the circulating blood, an increased blood volume causes more diluted CM [30]. Thus, an increased $\mathrm{CM}$ volume, for instance via additional optimisation to body weight, is needed in bigger patients to reach the same intravascular attenuation. Furthermore, the use of low kV settings increases the image noise in bigger patients, caused by the increased volume of surrounding tissue. A higher IDR and larger CM volume in patients with a higher BMI is needed. Indeed, although the study group was small, the $90 \mathrm{kV}$ group had no cases of non-diagnostic scans.

Previously used one-size-fits-all protocols, where every patient receives the same amount of CM volume (ca. $120 \mathrm{~mL})$ with the same $\mathrm{kV}$ setting $(120 \mathrm{kV})$, resulted in suboptimal image quality [22, 31]. Technical development in scan technique allow for usage of lower $\mathrm{kV}$ settings (70-90 kV). These lower $\mathrm{kV}$ settings, coming closer to the K-edge of iodine (33.2 keV), result in a higher intravascular attenuation [16]. Thus, lower CM volumes can be used with a $70 \mathrm{kV}$ scan acquisition compared to $120 \mathrm{kV}$. In the current study, the CM injection protocol was adapted to the tube voltage by adjusting the IDR based on a previously used $\mathrm{CM}$ injection protocol [22]. With every $10 \mathrm{kV}$ subtraction, the iodine dose can be reduced by $10 \%$ (10-to-10 rule) [21]. When using ATVS, the 10-to-10 rule can be used to adapt the CM injection protocol to tube voltage in CTA of the aorta.
The diagnostic image quality required for CTA of the aorta varies per indication; for instance, assessment of aorta diameters can be accomplished even at relatively low image quality, whereas assessment of aortic dissection, rupture or endoleakage post-EVAR requires the full picture. In the current study, the objective and subjective image quality was good to excellent in $99 \%$ of patients. Therefore, the proposed protocols may be used for all indications.

Disadvantages of CT imaging and administering CM are the use of radiation dose and the possible development of PC-AKI. Even though there is an ongoing discussion regarding the potential development of PC-AKI, guidelines still advocate preventive hydration in high-risk individuals to minimise the risk of PC-AKI [32, 33]. In addition, overall $\mathrm{CM}$ volume reduction is a straight forward method to minimise the risk as well. The current study showed that with adaptation of $\mathrm{CM}$ injection protocols to ATVS, CM volumes of $40 \mathrm{~mL}$ and $49 \mathrm{~mL}$ for respectively $70 \mathrm{kV}$ and $90 \mathrm{kV}$ are feasible. Furthermore, a low radiation dose is important in patients who require lifelong follow-up, to keep the cumulative radiation dose as low as possible in these patients. In the current study, ATVS assigned a tube voltage of $70 \mathrm{kV}$ and $90 \mathrm{kV}$ to almost all patients and this resulted in a radiation dose of $1.8 \mathrm{mSv}$ for $70 \mathrm{kV}$ and $3.4 \mathrm{mSv}$ for $90 \mathrm{kV}$. Unfortunately, the patient groups of $80 \mathrm{kV}$ and $100 \mathrm{kV}$ where too small for statistical analysis and had to be excluded. Higher $\mathrm{kV}$ settings (110 kV and $120 \mathrm{kV}$ ) were not assigned. An important factor contributing to lower tube voltage in this study is the pitch setting used; 0.6. CT scanners have a limitation with regard to the maximum photon output in a certain 
amount of time, which usually corresponds to a tradeoff between pitch and maximum tube output [34]. A low pitch corresponds to slower table movement and thus longer scan time. The scanner has enough time to provide a sufficiently high tube current to reach the desired diagnostic image quality. Consequently, a lower $\mathrm{kV}$ setting can be chosen by the software. With a high pitch the scan time decreases, the tube may not be able to provide a high enough tube current per second ( $\mathrm{mAs}$ ) required at low $\mathrm{kV}$ settings.

In the current study, the scanner assigned $70 \mathrm{kV}$ and $90 \mathrm{kV}$ to most patients. Previous studies with ATVS also found that a majority of CTA scans can be performed on the lower spectrum of possible $\mathrm{kV}$ settings $(80-90 \mathrm{kV})[15$, 35-37]. These studies did not scan any patient with $70 \mathrm{kV}$, whereas in our study $70 \mathrm{kV}$ was assigned in the majority of patients. Several explanations can be found: the different quality reference $\mathrm{kV}$ and $\mathrm{mAs}$, the slider position and pitch, the latter explained above. The quality reference $\mathrm{kV}$ and $\mathrm{mAs}$ can be set pre-acquisition to determine a user preferred image quality. Based on these references, the scanner calculates the optimal tube settings ( $\mathrm{kV}$ and $\mathrm{mAs})$ for each patient to reach a comparable image quality (CNR) as with the reference settings. With a higher reference $\mathrm{kV}$ and/or $\mathrm{mAs}$, higher tube settings are needed to ensure the same image quality and the software will increase $\mathrm{kV}$ and/or $\mathrm{mAs}$.

This study has some limitations. First, it is a single-centre study with a small population. A larger cohort might result in a larger number of patients chosen in higher $\mathrm{kV}$ settings (e.g. $100 \mathrm{kV}$ and $110 \mathrm{kV}$ ). Furthermore, a larger cohort would improve the power of the results. Secondly, this study was executed as a feasibility study and therefore did not focus on a direct comparison with a control group.

To conclude, adaptation of IDR to ATVS (70 kV and $90 \mathrm{kV}$ ) in CTA of the aorta is feasible and results in diagnostic image quality.

Funding Not applicable.

\section{Declarations}

Conflict of interest JEW receives institutional grants from AGFA, Bard, Bayer, GE, Optimed, Philips and Siemens and personal fees (speakers bureau) from Bayer and Siemens. MD receives institutional grants from Philips, Siemens and Bayer and personal fees (speakers bureau) from Cook, Siemens and Bayer. CM receives personal fees (speakers bureau) from Bayer and Siemens.

Open Access This article is licensed under a Creative Commons Attribution 4.0 International License, which permits use, sharing, adaptation, distribution and reproduction in any medium or format, as long as you give appropriate credit to the original author(s) and the source, provide a link to the Creative Commons licence, and indicate if changes were made. The images or other third party material in this article are included in the article's Creative Commons licence, unless indicated otherwise in a credit line to the material. If material is not included in the article's Creative Commons licence and your intended use is not permitted by statutory regulation or exceeds the permitted use, you will need to obtain permission directly from the copyright holder. To view a copy of this licence, visit http://creativecommons.org/licenses/by/4.0/.

\section{References}

1. Erbel R, Aboyans V, Boileau C, Bossone E, Bartolomeo RD, Eggebrecht H, et al. 2014 ESC Guidelines on the diagnosis and treatment of aortic diseases: document covering acute and chronic aortic diseases of the thoracic and abdominal aorta of the adult. The Task Force for the Diagnosis and Treatment of Aortic Diseases of the European Society of Cardiology (ESC). Eur Heart J. 2014;35(41):2873-926. https://doi.org/10.1093/eurheartj/ehu281.

2. Agarwal PP, Chughtai A, Matzinger FR, Kazerooni EA. Multidetector CT of thoracic aortic aneurysms. Radiographics. 2009;29(2):537-52. https://doi.org/10.1148/rg.292075080.

3. Soares Ferreira R, Bastos GF. Next generation post EVAR follow-up regime. J Cardiovasc Surg (Torino). 2017;58(6):875-82. https://doi.org/10.23736/S0021-9509.17.10100-X.

4. Hallett RL, Ullery BW, Fleischmann D. Abdominal aortic aneurysms: pre- and post-procedural imaging. Abdom Radiol (New York). 2018;43(5):1044-66. https://doi.org/10.1007/ s00261-018-1520-5.

5. Behrendt FF, Bruners P, Keil S, Plumhans C, Mahnken AH, Stanzel S, et al. Impact of different vein catheter sizes for mechanical power injection in CT: in vitro evaluation with use of a circulation phantom. Cardiovasc Intervent Radiol. 2009;32(1):25-31. https:// doi.org/10.1007/s00270-008-9359-8.

6. Bae KT, Tran HQ, Heiken JP. Uniform vascular contrast enhancement and reduced contrast medium volume achieved by using exponentially decelerated contrast material injection method. Radiology. 2004;231(3):732-6. https://doi.org/10.1148/radiol. 2313030497.

7. Mihl C, Wildberger JE, Jurencak T, Yanniello MJ, Nijssen EC, Kalafut JF, et al. Intravascular enhancement with identical iodine delivery rate using different iodine contrast media in a circulation phantom. Invest Radiol. 2013;48(11):813-8. https://doi.org/10. 1097/RLI.0b013e31829979e8.

8. Lameire NH. Contrast-induced nephropathy-prevention and risk reduction. Nephrol Dial Transplant. 2006;21(6):i11-23. https:// doi.org/10.1093/ndt/gfl215.

9. Aycock RD, Westafer LM, Boxen JL, Majlesi N, Schoenfeld EM, Bannuru RR. Acute kidney injury after computed tomography: a meta-analysis. Ann Emerg Med. 2018;71(1):44-53. https://doi. org/10.1016/j.annemergmed.2017.06.041.

10. Luk L, Steinman J, Newhouse JH. Intravenous contrast-induced nephropathy-the rise and fall of a threatening idea. Adv Chronic Kidney Dis. 2017;24(3):169-75. https://doi.org/10.1053/j.ackd. 2017.03.001.

11. Motta R, Rubaltelli L, Vezzaro R, Vida V, Marchesi P, Stramare R, et al. Role of multidetector CT angiography and contrast-enhanced ultrasound in redefining follow-up protocols after endovascular abdominal aortic aneurysm repair. Radiol Med. 2012;117(6):1079-92. https://doi.org/10.1007/ s11547-012-0809-x.

12. Brenner DJ, Hall EJ. Computed tomography-an increasing source of radiation exposure. N Engl J Med. 2007;357(22):227784. https://doi.org/10.1056/NEJMra072149.

13. Bischoff B, Hein F, Meyer T, Hadamitzky M, Martinoff S, Schomig A, et al. Impact of a reduced tube voltage on CT angiography and radiation dose: results of the PROTECTION I study. 
JACC Cardiovasc Imaging. 2009;2(8):940-6. https://doi.org/10. 1016/j.jcmg.2009.02.015.

14. Meinel FG, Canstein C, Schoepf UJ, Sedlmaier M, Schmidt B, Harris BS, et al. Image quality and radiation dose of low tube voltage 3rd generation dual-source coronary CT angiography in obese patients: a phantom study. Eur Radiol. 2014;24(7):1643-50. https://doi.org/10.1007/s00330-014-3194-x.

15. Winklehner A, Goetti R, Baumueller S, Karlo C, Schmidt B, Raupach R, et al. Automated attenuation-based tube potential selection for thoracoabdominal computed tomography angiography: improved dose effectiveness. Invest Radiol. 2011;46(12):767-73. https://doi.org/10.1097/RLI.0b013e3182266448.

16. Mahesh M. MDCT physics: the basics: technology, image quality and radiation dose. 1st ed. Philadelphia: Lippincott Williams and Wilkins; 2009.

17. Funama Y, Awai K, Nakayama Y, Kakei K, Nagasue N, Shimamura $\mathrm{M}$, et al. Radiation dose reduction without degradation of low-contrast detectability at abdominal multisection CT with a low-tube voltage technique: phantom study. Radiology. 2005;237(3):905-10. https://doi.org/10.1148/radiol.2373041643.

18. Nakayama Y, Awai K, Funama Y, Hatemura M, Imuta M, Nakaura $\mathrm{T}$, et al. Abdominal CT with low tube voltage: preliminary observations about radiation dose, contrast enhancement, image quality, and noise. Radiology. 2005;237(3):945-51. https://doi.org/10. 1148/radiol.2373041655.

19. Kok M, Mihl C, Hendriks BM, Altintas S, Kietselaer BL, Wildberger JE, et al. Optimizing contrast media application in coronary CT angiography at lower tube voltage: evaluation in a circulation phantom and sixty patients. Eur J Radiol. 2016;85(6):1068-74. https://doi.org/10.1016/j.ejrad.2016.03.022.

20. Kok M, Mihl C, Seehofnerova A, Turek J, Jost G, Pietsch H, et al. Automated tube voltage selection for radiation dose reduction in CT angiography using different contrast media concentrations and a constant iodine delivery rate. Am J Roentgenol. 2015;205(6):1332-8. https://doi.org/10.2214/AJR.14.13957.

21. KorporaalLG. Reduction of contrast agent dose at low $\mathrm{kV}$ settings. 2017.

22. Kok M, de Haan MW, Mihl C, Eijsvoogel NG, Hendriks BM, Sailer AM, et al. Individualized CT angiography protocols for the evaluation of the aorta: a feasibility study. J Vasc Interv Radiol. 2016;27(4):531-8. https://doi.org/10.1016/j.jvir.2016.01.009.

23. SHwG K. CARE kV: automated dose-optimized selection of X-ray tube voltage. 2011. https://www.usahealthcaresiemenscom/sieme ns_hwemhwem_ssxa_websites-contextroot/wcm/idc/groups/publi c/@us/@imaging/documents/download/mdaw/ndq2/ edisp/low_ dose_carekv-00308417pdf. Accessed 2017.

24. The 2007 Recommendations of the International Commission on Radiological Protection. ICRP publication 103. Ann ICRP. 2007;37(2-4):1-332. https://doi.org/10.1016/j.icrp.2007.10.003.

25. Bae KT. Optimization of contrast enhancement in thoracic MDCT. Radiol Clin N Am. 2010;48(1):9-29. https://doi.org/10.1016/j.rcl. 2009.08.012.

26. Weininger M, Barraza JM, Kemper CA, Kalafut JF, Costello P, Schoepf UJ. Cardiothoracic CT angiography: current contrast medium delivery strategies. Am J Roentgenol. 2011;196(3):W260-72. https://doi.org/10.2214/AJR.10.5814.
27. Leipsic J, Labounty TM, Heilbron B, Min JK, Mancini GB, Lin FY, et al. Adaptive statistical iterative reconstruction: assessment of image noise and image quality in coronary CT angiography. Am J Roentgenol. 2010;195(3):649-54. https://doi.org/10.2214/ AJR.10.4285.

28. Kok M, Turek J, Mihl C, Reinartz SD, Gohmann RF, Nijssen EC, et al. Low contrast media volume in pre-TAVI CT examinations. Eur Radiol. 2016;26(8):2426-35. https://doi.org/10.1007/ s00330-015-4080-X.

29. Nishii T, Watanabe Y, Shimoyama S, Kono AK, Sofue K, Mori $\mathrm{S}$, et al. Tailored duration of contrast material injection in highpitch computed tomographic aortography with a double-level test bolus method. Invest Radiol. 2017;52(5):274-80. https://doi.org/ 10.1097/RLI.0000000000000340.

30. Bae KT. Intravenous contrast medium administration and scan timing at CT: considerations and approaches. Radiology. 2010;256(1):32-61. https://doi.org/10.1148/radiol.10090908.

31. Hendriks BM, Kok M, Mihl C, Bekkers SC, Wildberger JE, Das $\mathrm{M}$. Individually tailored contrast enhancement in CT pulmonary angiography. Br J Radiol. 2016;89(1061):20150850. https://doi. org/10.1259/bjr.20150850.

32. Nijssen EC, Rennenberg RJ, Nelemans PJ, Essers BA, Janssen MM, Vermeeren MA, et al. Prophylactic hydration to protect renal function from intravascular iodinated contrast material in patients at high risk of contrast-induced nephropathy (AMACING): a prospective, randomised, phase 3, controlled, open-label, non-inferiority trial. Lancet. 2017;389(10076):1312-22. https:// doi.org/10.1016/S0140-6736(17)30057-0.

33. Nijssen EC, Nelemans PJ, Rennenberg RJ, van Ommen V, Wildberger JE. To hydrate or not to hydrate? Lessons learned from the AMACING trial. Chin J Acad Radiol. 2019;1(1):2-5. https://doi. org/10.1007/s42058-019-00008-z.

34. Tack D, Kalra MK, Gevenois PA. Radiation dose from multidetector CT. Berlin: Springer; 2012.

35. Goetti R, Winklehner A, Gordic S, Baumueller S, Karlo CA, Frauenfelder T, et al. Automated attenuation-based kilovoltage selection: preliminary observations in patients after endovascular aneurysm repair of the abdominal aorta. Am J Roentgenol. 2012;199(3):W380-5. https://doi.org/10.2214/AJR.11.8029.

36. Lurz M, Lell MM, Wuest W, Eller A, Scharf M, Uder M, et al. Automated tube voltage selection in thoracoabdominal computed tomography at high pitch using a third-generation dual-source scanner: image quality and radiation dose performance. Invest Radiol. 2015;50(5):352-60. https://doi.org/10.1097/RLI.00000 00000000133.

37. Nijhof WH, Baltussen EJ, Kant IM, Jager GJ, Slump CH, Rutten MJ. Low-dose CT angiography of the abdominal aorta and reduced contrast medium volume: assessment of image quality and radiation dose. Clin Radiol. 2016;71(1):64-73. https://doi. org/10.1016/j.crad.2015.10.007.

Publisher's Note Springer Nature remains neutral with regard to jurisdictional claims in published maps and institutional affiliations. 